\title{
PELATIHAN GOOGLE APPS BAGI GURU SMK NEGERI 3 PALEMBANG
}

\author{
Ervi Cofriyanti ${ }^{1)}$, Irma Salamah ${ }^{2)}$, Lindawati ${ }^{3)}$ \\ ${ }^{1}$ Teknik Komputer, Politeknik Negeri Sriwijaya \\ e-mail: ervi@polsri.ac.id \\ ${ }^{2,3}$ Teknik Telekomunikasi, Politeknik Negeri Sriwijaya \\ e-mail: irma.salamah@yahoo.com, lindawati9111@yahoo.com
}

\begin{abstract}
The purpose of the community service program is to improve the knowledge and skills of vocational school teachers, especially SMK Negeri 3 Palembang (Public Vocational High School 3 Palembang) about the utilization of information technology, namely the application of Google Apps such as Gmail, Google Drive, Google Doc-Forms and Google Calendar. They can be used to support the learning-teaching dan teacher's working processes at school. The method of implementing the activity consists of several phases, namely planning phase, implementation phase, observation-evaluation phase and reflection phase. Community service activities are carried out within 6 months. At the beginning and ending of the training, the participants are given a questionnaire (pre-test and post-test) to find out the understanding level of participants. Based on the results of the questionnaire recapitulation on May 30 ${ }^{\text {th }}, 2018$, as a result of the reflection of the entire community service activities, $62.5 \%$ respondents are answered the knowledge/ technique mastered by the participants after the Google Apps training, 62.5\% of the participants answered the instructor's guidances are quite easy to understand, and as many as $87.5 \%$ of participants stated that the training content and method, as well as training design were satisfying.
\end{abstract}

Keywords: Community Service, Google Apps, Public Vocational High School 3 Palembang.

\section{PENDAHULUAN}

Menurut [1] bahwa pasca pemilu ini pendidikan nasional memiliki tiga tantangan yaitu pertama, tantangan dalam menghadapi bonus demografi. Jumlah penduduk Indonesia pada tahun 2035 diproyeksikan mencapai 305,6 juta jiwa. Meningkatnya jumlah penduduk Indonesia tentu saja akan disertai dengan meningkatnya penduduk berusia produktif (usia 15 tahun sampai 65 tahun). Inilah yang akan kita hadapi dalam periode bonus demografi, yaitu rasio ketergantungan terhadap penduduk tak produktif. Alhasil, penduduk Indonesia yang produktif diperkirakan akan lebih banyak daripada penduduk yang tak produktif. Fenomena ini harus didukung kebijakan ekonomi, pendidikan, sosial, dan kesehatan dalam merespons bonus demografis tersebut.

Kebijakan pendidikan adalah kunci utama dalam pembangunan nasional yang memiliki efek jangka panjang berkelanjutan. Kedua, tantangan merespons perubahan di tingkat regional atas pemberlakuan Masyarakat ASEAN 2015. Tantangan ketiga adalah kualitas guru yang menjadi kunci sekaligus faktor vital pendidikan nasional. Pendidikan di mana pun berada kuncinya terletak pada kualitas guru. Kurikulum canggih tanpa didukung guru-guru yang canggih sama dengan mimpi di siang bolong. Masa depan pendidikan Indonesia berada pada kualitas guru yang mumpuni. Secara umum, kualitas guru dan kompetensi guru di Indonesia masih belum sesuai dengan yang diharapkan [2]. Kualitas guru mengacu pada dua kemampuan, yaitu 
kemampuan akademik dan kemampuan non akademik. Salah satu kemampuan akademik guru yaitu terkait teknologi informasi yang sangat penting untuk mendukung pekerjaan kantor maupun kegiatan belajar-mengajar. Tak terkecuali pada guru sekolah kejuruan yang ada di Indonesia, khususnya SMK Negeri 3 Palembang.

Berdasarkan hasil wawancara dengan Wakasek Humas SMK Negeri 3 Palembang, Bapak Junaidi yang dilakukan pada tanggal 17 Januari 2018, diperoleh informasi bahwa para guru masih belum terlalu paham penggunaan teknologi informasi seperti penggunaan e-mail (electronic mail atau surat yang berbentuk elektronik, termasuk alat komunikasi yang murah dan cepat [3]), ataupun menggunakan aplikasi-aplikasi program yang dapat digunakan untuk mendukung kegiatan belajarmengajar maupun kegiatan perkantoran. Sehingga masih belum dapat mencapai misi/tujuan SMK Negeri 3 Palembang yaitu menghasilkan lulusan siswa yang beriman,

berakhlak mulia, berpengetahuan luas, menguasai teknologi, kreatif, inovatif dan profesional, karena sebagian besar gurunya masih belum terpaham penggunaan teknologi informasi.

Mempertimbangkan jumlah guru SMK Negeri 3 Palembang yang cukup banyak yaitu kurang lebih 30 orang, dengan pemahaman yang masih kurang dalam pemanfaatan teknologi informasi, maka Kepala Sekolah SMK Negeri 3 Palembang bersama pelaksana kegiatan pengabdian kepada masyarakat kerja sama dosenmahasiswa memandang perlu untuk mengadakan kegiatan pelatihan yang melibatkan para guru SMK Negeri Palembang dengan memberikan materi pelatihan mengenai Google Apps yaitu serangkaian alat produktivitas komputasi awan dan perangkat lunak kolaborasi serta perangkat lunak yang ditawarkan secara berlangganan di Google [4]. Tetapi aplikasi-aplikasi Google ini tidak berbayar, hanya dengan membuat akun saja di Gmail (layanan e-mail web Google [4]). Adapun materi pelatihan Google Apps yang akan diberikan meliputi Gmail, Google Drive (layanan penyimpanan dan sinkronisasi file Google [4]), Google Doc dan Form (editor online untuk membuat dokumen teks atau format file dokumen, spreadsheet, presentasi, dan survei [4]) serta Google Calendar (kalender online terintegrasi dan dapat digunakan bersama yang dirancang untuk tim [4]).

Kepala Sekolah SMK Negeri 3 Palembang sangat berharap kegiatan ini dapat dilaksanakan segera. Hal ini dikarenakan para guru SMK Negeri 3 Palembang sangat memerlukan "penyegaran" terkait pemanfaatan teknologi informasi, agar digunakan untuk mendukung kegiatan belajarmengajar dan kegiatan perkantoran sehingga dapat mengembangkan kemampuan profesionalisme para guru. Kegiatan ini akan dilaksanakan dalam waktu 6 bulan atau 24 minggu. Para guru MGMP akan dibagi menjadi 3 kelompok yang terdiri dari lebih kurang 10 orang didampingi 1 instruktur dan 1 asisten mahasiswa agar kegiatan pelatihan lebih efektif.

\section{IDENTIFIKASI MASALAH}

Berdasarkan analisis situasi pada bagian sebelumnya, maka terlihat bahwa masih kurangnya kemampuan guru SMK Negeri 3 Palembang untuk memanfaatkan teknologi informasi. Dengan demikian permasalahan yang timbul adalah:

Bagaimana memberikan pengetahuan dan pemahaman kepada guru SMK Negeri 3 Palembang tentang cara-cara penggunaan Google Apps seperti Gmail, Google Drive, Google Doc dan Form serta Google Calendar untuk mendukung kegiatan perkantoran mapun belajar-mengajar?

\section{METODOLOGI PELAKSANAAN}

Metode pelaksanaan kegiatan pengabdian kepada masyarakat ini dilakukan dengan mengadopsi langkah-langkah action research yang terdiri atas 4 (empat) tahapan, yaitu perencanaan, tindakan, observasi dan evaluasi, serta refleksi [5].

1) Perencanaan

Pada tahapan perencanaan ini, tim pelaksana melakukan survei awal dahulu dengan melakukan wawancara kepada pihak mitra yaitu Kepala Sekolah SMK Negeri 3 Palembang yang diwakili oleh Wakasek Humas, Bapak Junaidi. Hal ini dilakukan untuk mengidentifikasi permasalahan dan solusi yang dapat 
ditawarkan kepada pihak mitra yaitu berupa program pelatihan. Selanjutnya disusun program pelatihan sebagai berikut :

a) Para guru akan dibagi menjadi 3 kelompok dengan pembagian sebagai berikut.

\begin{tabular}{|c|c|c|}
\hline $\begin{array}{c}\text { No. } \\
\text { Kelompok }\end{array}$ & $\begin{array}{c}\text { Jumlah } \\
\text { Anggota }\end{array}$ & $\begin{array}{c}\text { Jumlah } \\
\text { Pendamping }\end{array}$ \\
\hline 1 & 10 orang & $\begin{array}{c}1 \text { instruktur dan 1 } \\
\text { asisten } \\
\text { mahasiswa }\end{array}$ \\
\hline 2 & 10 orang & $\begin{array}{c}1 \text { instruktur dan 1 } \\
\text { asisten } \\
\text { mahasiswa }\end{array}$ \\
\hline 3 & 10 orang & $\begin{array}{c}1 \text { instruktur dan 1 } \\
\text { asisten } \\
\text { mahasiswa }\end{array}$ \\
\hline Total & $\begin{array}{c}\mathbf{3 0} \\
\text { orang }\end{array}$ & \\
\hline
\end{tabular}

b) Program pelatihan akan dilakukan dalam waktu 6 bulan dengan susunan materi sebagai berikut.

\begin{tabular}{|c|l|l|}
\hline No. & \multicolumn{1}{|c|}{ Agenda } & \multicolumn{1}{|c|}{$\begin{array}{c}\text { Materi tes } \\
\text { evaluasi }\end{array}$} \\
\hline 1 & $\begin{array}{l}\text {-Penggunaan Gmail } \\
\text { dan Google Drive }\end{array}$ & - \\
\hline 2 & $\begin{array}{l}\text {-Penggunaan } \\
\text { Google Doc dan } \\
\text { Form }\end{array}$ & - \\
\hline 3 & $\begin{array}{l}\text {-Penggunaan } \\
\text { Google Calendar } \\
\text {-Evaluasi }\end{array}$ & $\begin{array}{l}\text {-Pemberian } \\
\text { kuesioner } \\
\text { untuk } \\
\text { evaluasi } \\
\text { kegiatan. }\end{array}$ \\
\hline
\end{tabular}

2) Tindakan

Tindakan dalam kegiatan ini berupa implementasi program. Kegiatan-kegiatan yang dilakukan dalam implementasi program yaitu :

a) Pelatihan cara penggunaan e-mail Gmail dan Google Drive.

b) Pelatihan cara menggunakan menumenu/tools pada Google Doc dan Form.

c) Pelatihan cara menggunakan menumenu/tools pada Google Calendar.

3) Observasi dan Evaluasi

Observasi dilakukan selama proses pelatihan terhadap pihak mitra seperti kendala-kendala yang muncul dalam proses pelatihan di kelas. Instrumen yang digunakan berupa catatan lapangan. Evaluasi dilakukan satu kali setelah pemberian materi mengenai Google Apps.

4) Refleksi
Refleksi dilakukan terhadap kegiatan yang telah dilaksanakan dengan memberikan kuesioner evaluasi kepada pihak mitra. Hal ini dilakukan semata-mata untuk mengetahui kekurangan atau kelebihan terhadap kegiatan yang telah dilakukan dalam rangka untuk menetapkan rekomendasi terhadap keberlangsungan atau pengembangan kegiatan-kegiatan berikutnya. Tahap berikutnya yaitu pembuatan laporan kegiatan pengabdian kepada masyarakat yang berisi semua hasil pelaksanaan kegiatan.

\section{HASIL DAN PEMBAHASAN}

Untuk kegiatan pengabdian kepada masyarakat ini, kegiatan yang telah dilakukan terlihat pada Tabel 1.

\section{Tabel 1 Rencana Kegiatan yang Telah} Dilaksanakan

\begin{tabular}{|l|l|}
\hline $\begin{array}{l}\text { Rencana Kegiatan yang } \\
\text { Telah Dilakukan }\end{array}$ & $\begin{array}{c}\text { Waktu } \\
\text { Pelaksanaan }\end{array}$ \\
\hline $\begin{array}{l}\text { Perencanaan/Persiapan, } \\
\text { pembuatan program } \\
\text { kerja/jadwal, koordinasi }\end{array}$ & April 2018 \\
dengan pihak MGMP \\
Matematika SMP Gugus \\
SMP Negeri 15 \\
Palembang.
\end{tabular}

Berdasarkan hasil kuesioner pre dan post pelatihan yang diberikan pada tanggal $30 \mathrm{Mei}$ 2018 mengenai pelatihan Google Apps yang telah diberikan dapat dirangkum sebagai berikut:

1) Sebelum pelatihan sebanyak $66,67 \%$ dari 18 orang peserta menyatakan pernah menggunakan aplikasi Google untuk membantu proses belajar mengajar atau dalam kegiatan perkantoran dan sebanyak $33,33 \%$ menyatakan tidak pernah menggunakannya. Sedangkan sebanyak $55,56 \%$ dari 18 peserta menjawab dapat dengan lancar menggunakan aplikasi Google dan 44,45\% menjawab kurang 
dan bahkan tidak lancar menggunakannya, hal ini dapat dikarenakan belum familiarnya peserta dengan aplikasi Google seperti Google Drive, Google Doc and Form, dan Google Calendar.

2) Sesudah pelatihan mengenai aplikasi Google, sebanyak $87,5 \%$ menjawab masih kurang lancar menggunakan aplikasi Google, hal ini lebih dikarenakan koneksi jaringan internet yang lambat sehingga peserta kesulitan dalam mengakses aplikasi Google secara cepat via laptop atau hp. Sedangkan jika dilihat dari sisi isi, metode dan desain pelatihan sebanyak $87,5 \%$ menjawab sudah memuaskan. Selain itu secara keseluruhan, rata-rata $62,5 \%$ pengetahuan/teknik dikuasai peserta setelah pelatihan berdasarkan hasil kuesioner post pelatihan.

Sedangkan berdasarkan hasil rekapitulasi kuesioner pada tanggal 30 Mei 2018 sebagai hasil refleksi keseluruhan kegiatan pengabdian kepada masyarakat dapat dirangkum beberapa hal sebagai berikut :

1) Sebanyak $62,5 \%$ menjawab pengetahuan/teknik dikuasai peserta setelah pelatihan Google Apps.

2) Terkait bimbingan yang diberikan oleh instruktur dalam pelatihan sebanyak $62,5 \%$ peserta menjawab cukup mudah untuk dimengerti.

3) Sebanyak $87,5 \%$ peserta menyatakan bahwa isi dan metode bimbingan, serta desain pelatihan memuaskan.

4) Adapun saran yang diberikan untuk panitia pelaksana pelatihan yaitu supaya pelatihan ini dapat dilanjutkan lagi di masa yang akan datang dan diberikan materi mengenai Google Apps lebih mendetail lagi selain yang telah diajarkan, serta perlu dipertimbangkan untuk kedepannya jika mengadakan pelatihan mengenai Google Apps mengenai dukungan tempat/ruang yang terkoneksi jaringan internet yang cukup baik sehingga pelaksanaan pelatihan dapat berjalan dengan lancar.

Gambar 1 menunjukkan foto dokumentasi kegiatan pengabdian kepada masyarakat yang telah dilaksanakan.

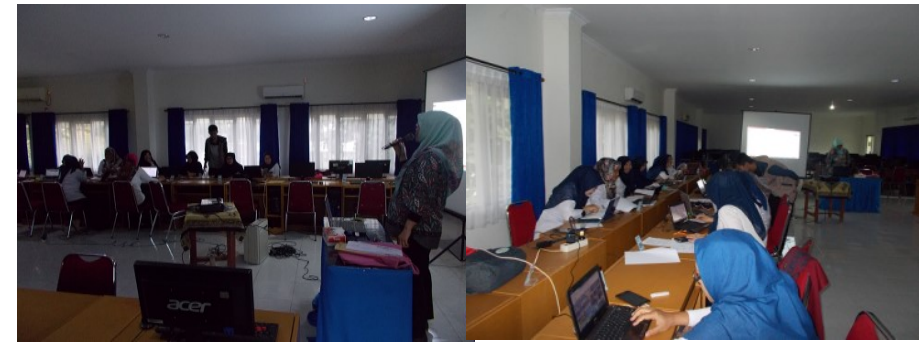

Gambar 1 Foto Dokumentası Kegiatan

\section{KESIMPULAN}

Berdasarkan hasil rekapitulasi kuesioner pada tanggal 30 Mei 2018 sebagai hasil refleksi keseluruhan kegiatan pengabdian kepada masyarakat dapat disimpulkan beberapa hal sebagai berikut:

1. Sebanyak $62,5 \%$ menjawab pengetahuan/teknik dikuasai peserta setelah pelatihan Google Apps.

2. Terkait bimbingan yang diberikan oleh instruktur dalam pelatihan sebanyak $62,5 \%$ peserta menjawab cukup mudah untuk dimengerti.

3. Sebanyak $87,5 \%$ peserta menyatakan bahwa isi dan metode bimbingan, serta desain pelatihan memuaskan.

Adapun saran yang diberikan peserta kepada panitia pelaksana pelatihan yaitu kegiatan pengabdian kepada masyarakat ini diharapkan dapat dilanjutkan lagi di masa yang akan datang dan diberikan materi mengenai Google Apps lebih mendetail lagi selain yang telah diajarkan, serta perlu dipertimbangkan untuk kedepannya jika mengadakan pelatihan mengenai Google Apps mengenai dukungan tempat/ruang yang terkoneksi jaringan internet yang cukup baik sehingga pelaksanaan pelatihan dapat berjalan dengan lancar.

\section{UCAPAN TERIMA KASIH}

Penulis mengucapkan terima kasih kepada pihak Politeknik Negeri Sriwijaya atas support Dana Pengabdian PNBP Polsri 2018 untuk kegiatan pengabdian kepada masyarakat ini dan pihak SMK Negeri 3 Palembang yang telah memberi data dan informasi yang diperlukan untuk makalah ini.

\section{REFERENSI}

[1] "Tiga tantangan pendidikan nasional." [Online]. Available: https://nasional.sindonews.com $/ \mathrm{read} / 8582$ 44/18/tiga-tantangan-pendidikannasional-1398642945. [Accessed: 04May-2017]. 
[2] "Kualitas Guru Masih Rendah.” [Online]. Available:

https://edukasi.kompas.com/read/2012/03 /07/08304834/Kualitas.Guru.Masih.Rend ah. Rabu 7 Maret 2012. [Accessed: 04May-2017].

[3] "Pengertian Email dan Fungsi serta manfaatnya." [Online]. Available:

http://www.pintarkomputer.org/2015/02/p engertian-email.html\#. [Accessed: 29-Jul2016].

[4] "Google Apps." [Online]. Available: https://id.wikipedia.org/wiki/Google_App s. [Accessed: 05-Feb-2018].

[5] D. I. K. Penebel, N. N. Parwati, M. Pd, and K. T. Pelaksana, "Laporan pengabdian kepada masyarakat program ipteks bagi masyarakat (IbM)," 2013. 